\title{
Statyba
}

\section{THE INTERACTION ESTIMATION OF PILES BORED IN SAND}

\section{Sližytė}

To cite this article: D. Sližyte (2001) THE INTERACTION ESTIMATION OF PILES BORED IN SAND, Statyba, 7:5, 405-412, DOI: 10.1080/13921525.2001.10531762

To link to this article: https://doi.org/10.1080/13921525.2001.10531762

曲 Published online: 30 Jul 2012.

Submit your article to this journal \lceil

山 Article views: 67

7 Citing articles: 1 View citing articles 


\section{CENTRIŠKAI APKRAUTŲ GRĘŽTINIŲ POLIŲ SĄVEIKOS VERTINIMAS}

\section{Sližytè}

\section{Vilniaus Gedimino technikos universitetas}

\section{Ivadas}

Didejant pastatų aukštingumui, pamatai pagrindui turi perduoti $10 \mathrm{MN}$ siekiančias apkrovas. Tokio dydžio apkrovoms perduoti dažnai tenka ịrengti polinius pamatus, kuriuos sudaro polių grupès. Šiuo metu populiarejantys gręžtiniai poliai taip pat dažnai ịrengiami grupèmis, tačiau jų projektavimui skirtose normose „Gręžininių pamatų projektavimas ir statyba RSN 91-85" [1] yra nurodoma, kaip projektuoti atskiruosius gręžtinius polius. $[2,3]$ pabréžiama, kad atskirojo polio nuosèdžiai visada bus mažesni nei tokio pat polio, esančio polių grupèje, ir tai susiję su didesne ar mažesne šalia esančių polių itaka. Vienas iš būdų projektuoti polinius pamatus taikant atskirojo polio statinio bandymo rezultatus yra aprašytas [4]. Čia taikomas itakos koeficientas, aprašantis papildomus polio nuosèdžius, atsirandančius dèl šalia esančio apkrauto polio itakos. Pagrindinè problema, neleidžianti plačiai taikyti šio poliniu pamatú projektavimo metodo, yra ta, kad nèra tikslaus itakos koeficiento skaičiavimo metodo.

Šiame straipsnyje pateikiamas metodas, kaip, aprašius konkretaus polio apkrovos nuosėdžių priklausomybę, rasti jtakos koeficientą.

\section{Dviejų polių sąveikos vertinimas}

1968 m. australas Poulos'as [5] pasiūlè gręžtiniụ poliụ sąveiką nagrinèti remiantis dviejų polių grupès pavyzdžiu. Buvo pasirinkti gręžtiniai poliai, kadangi juos irengiant pagrinde nesukeliami papildomi ịtempimai. $i$-asis polis yra apkrautas tam tikra apkrova $N$, dèl to pasiekia $s$ nuosèdi. Tačiau aplink poli yra gruntas, kuris, perimdamas apkrovą, seda kartu su poliu. Apkrova, tolstant nuo polio, perima vis didesnè zona, todél ir gruntas tolstant nuo polio sèda vis mažiau. Bet tam tikru atstumu yra $j$-asis polis. Dabar jau ji supantis grun- tas, sèsdamas paskui save tempia $j$-aji polị. Taigi susidaro tam tikra polis-gruntas-polis sistema, kurios kiekvieno elemento savybès turès itakos visos sistemos darbui. Šios sistemos darbą Poulos'as pasiūle ịvertinti sąveikos koeficientu:

$$
\alpha_{i j}=\frac{s_{j i}}{s_{i}},
$$

$s_{j i}-j$-ojo polio nuosedis dèl $i$-ojo polio itakos ( 1 pav.), $s_{i}-i$-ojo polio nuosedis nuo pridetos ašinès apkrovos.

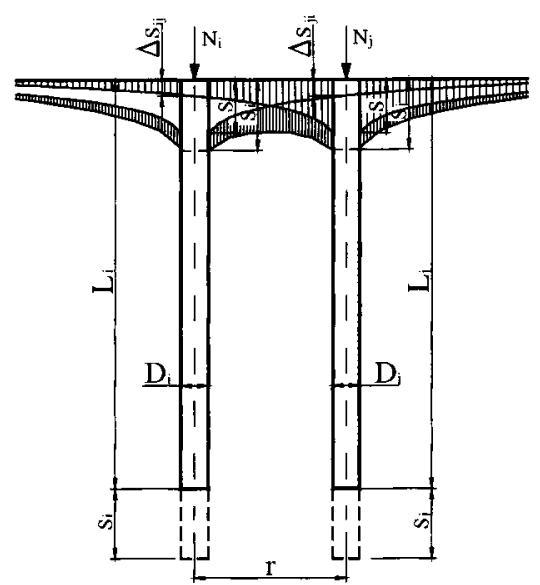

1 pav. Dviejų vienodų poliu grupè

Fig 1. The group of two identical piles

Kai vienodo ilgio poliai yra irengti smèliniuose gruntuose ir polio padas neatremtas i standụ pagrindą, sąveikos koeficientas priklauso nuo šių pagrindinių polis-gruntas-polis sistemos parametrų:

- nuo grunto charakteristikų: šlyties deformacijų modulio $G$ bei Puasono koeficiento n;

- nuo polio charakteristikų: polio santykinio ilgio $L / D$, santykinio polio-grunto standumo $K=E_{p} / E_{0}(z=L / 2)$, rodančio, kiek kartų polio deformacijų modulis yra didesnis už grunto mažų deformacijų tamprumo modulị $L / 2$ gylyje; 
- nuo padéties plane: santykinio atstumo nuo polio ašies $r / D$.

Nors poliu tarpusavio squveika vertinama jau daugiau kaip 30 metụ, tačiau, taikant ši metodą praktikoje problemų kyla dèl sąveikos koeficiento skaičiavimo metodo. [6] pateikti keturi skaičiavimo metodai, pagal kuriuos, naudojant tuos pačius pradinius duomenis, buvo apskaičiuoti sqaveikos koeficientai (2 pav.).

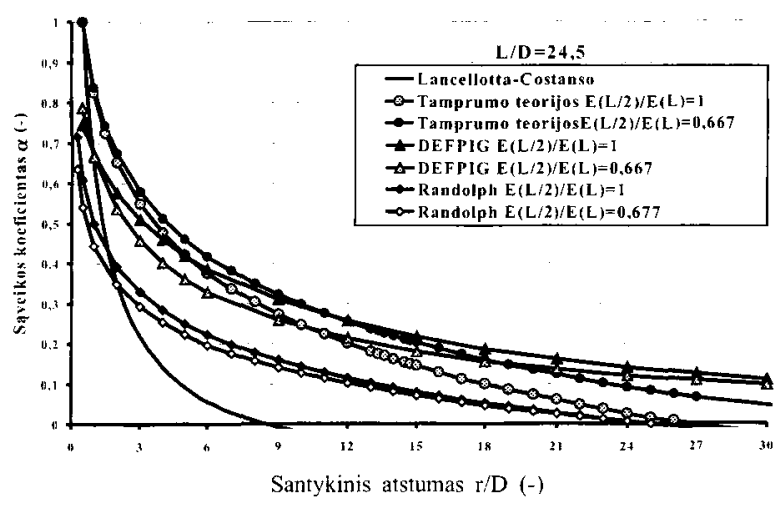

2 pav. Sąveikos koeficiento priklausomybè nuo santykinio atstumo $r / D$ bei skaičiavimo metodo

Fig 2. Interaction coefficient relationship for normalised pile spacing $r / D$ and calculating method

Taikant šiuos įtakos koeficiento skaičiavimo metodus gali būti naudojami trys šlyties deformacijų modulio kitimo modeliai:

- šlyties deformaciju modulis yra pastovus ir lygus mažų šlyties deformacijų moduliui;

- šlyties deformaciju modulis spindulio kryptimi kinta pagal tiesinę priklausomybę [7] (3 pav.): polio-grunto kontakto vietoje šlyties deformacijų modulis yra 4 kartus mažesnis už $8,5 \mathrm{D}$ nuo apkrauto polio ašies esančio grunto šlyties deformaciju moduli, kuris lygus mažu šlyties deformacijų šlyties moduliui: $G / G_{0}=0,25$;

- šlyties deformacijų modulis spindulio kryptimi kinta pagal tiesinę priklausomybę ( 3 pav.): polio-grunto kontakto vietoje šlyties deformaciju modulis yra 10 kartų mažesnis už $8,5 \mathrm{D}$ nuo apkrauto polio ašies esančio grunto šlyties deformacijų moduli, kuris lygus mažų šlyties deformaciju šlyties moduliui: $G / G_{0}=0,10$.

Tačiau, kaip rodo V. N. Ghionna ir kt. tyrimai [8], šlyties deformaciju modulis polio-grunto kontakto vietoje nera pastovus dydis ir priklauso nuo apkrauto polio santykinių nuosèdžių (4 pav.) Be to, šlyties deformaciju modulis priklauso nuo grunto šlyties deformaci- ju [9], todẻl ir šio modulio kitimas spindulio kryptimi bei kitimo spindulys turi priklausyti nuo grunte veikiančių tangentinių ittempimų. Imant konkretụ ịtakos zonos spinduli bei konkretu pastovų $G / G_{0}$ santyki lieka neivertintas įtakos koeficiento pokytis dèl grunte besikeičiančių ịtempimų.

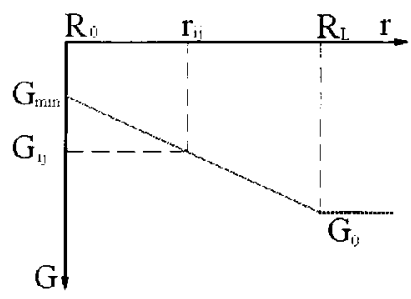

3 pav. Šlyties deformaciju modulio kitimas spindulio kryptimi pagal D. Costanzo ir R. Lancellotta [7]

Fig 3. The variation of shear deformation modulus by D. Costanzo and R. Lancellotta [7]

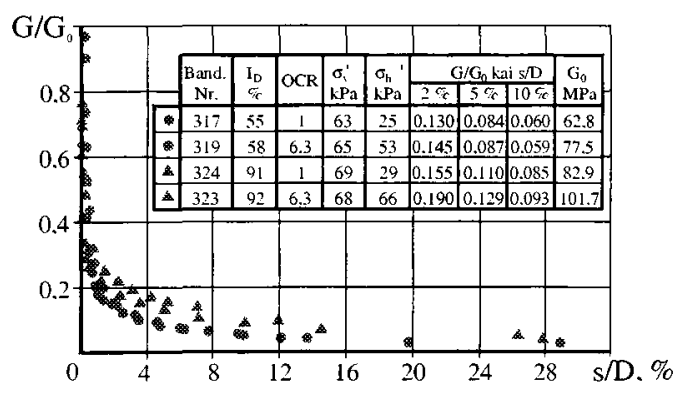

4 pav. $G / G_{0}$ priklausomybè nuo polio santykinio nuosèdžio $s / D$ vidutinio tankumo ir tankiam smèliui [8]

Fig 4. $G / G_{0}$ relationship for normalised settlement $s / D$ of medium dense and dense sand [8]

$\mathrm{Be}$ to, visos nagrinètos metodikos remiasi prielaida, kad centriškai apkrauto polio itaka greta esantiems poliams yra analogiška, kaip ir jo itaka gruntui, slūgsančiam ties polio vidurio linija. Tačiau [10] parodè, kad grunto, esančio aplink polị, nuosèdžiai polio pado lygyje yra mažiausi, palyginti su aukščiau esančio grunto nuosèdžiais (5 pav.).

Iš pateiktụ priklausomybių galima spręsti, kad, nors visi literatūroje rasti skaičiavimo metodai paremti tamprumo teorijos dèsniais, tačiau gauti rezultatai yra išsibarstę dideliu intervalu, - kai santykinis atstumas $r / D=3$, didžiausia sąveikos koeficiento reikšmè yra net $2,65 \mathrm{kar}$ tụ didesnè nei mažiausia gauta reikšmè. Taip pat nèra itakos koeficiento, įvertinančio visus jam turinčius ịta- 
kos veiksnius. Gali būti keistinos ir prielaidos. O kuris iš šiuo metu taikomų skaičiavimo metodų yra tikslesnis, galima pasakyti tik sulyginus skaičiavimo rezultatus su eksperimentiniais.

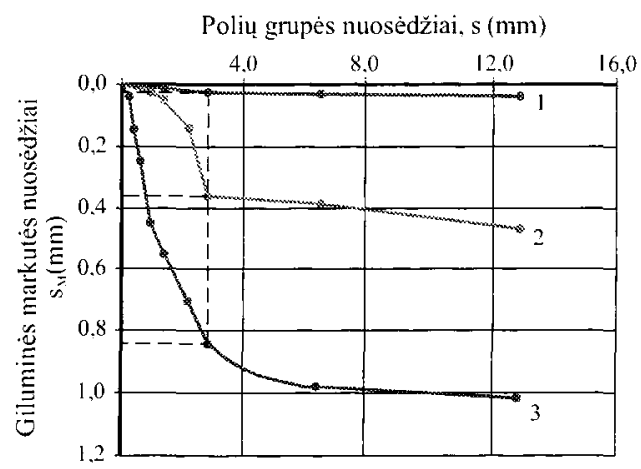

5 pav. Grunto šalia apkrauto polio nuosèdžiai priklausomai nuo gylio pagal L. Furmonavičių [10]: 1 - giluminé markute $1,87 \mathrm{~m}$ gylyje (polio pado lygyje); $2-0,90 \mathrm{~m}$ gylyje; $3-0,30 \mathrm{~m}$ gylyje

Fig 5. The settlement of soil near loaded pile relationship for measured depth by L. Furmonavičius. [10]: 1 depth-mark at $1,87 \mathrm{~m}$ depth (pile base level), 2 - at $0.90 \mathrm{~m}$ depth, 3 - at $0.30 \mathrm{~m}$ depth

\section{Polių grupių fizikinio modeliavimo centrifugoje re- zultatai}

ISMES (Bergamo, Italija) Geotechnikos laboratorijoje atlikti 25 gręžtinių polių grupiụ bandymai geotechnineje centrifugoje. Naudoti dviejų tipu smèliai: Toyouros (TOS) - vidutinio tankumo bei tankus vienalytis vidutinio rupumo kvarcinis smèlis ir dirbtinès kilmès tankus vienalytis labai smulkus kvarcinis smèlis (sutrumpintai FFS).

Naudojant du modeliavimo mastelius buvo tirti dvieju geometrinių matmenų poliai, kurių skersmuo $D=0,314 \mathrm{~m}$ ir $0,838 \mathrm{~m}$ bei ilgis atitinkamai $L=7,695 \mathrm{~m}$ ir $20,519 \mathrm{~m}$.

Kad būtu galima išsiaiškini, kokią įtaką sąveikos koeficientui turi polio šoninio paviršiaus šiurkštumas, buvo naudoti poliai, kurių šoninio paviršiaus santykinis šiurkštumas: Toyouros smèlyje lygių polių $R_{n}=0,05$ ir šiurkščiụ poliụ $R_{n}=0,45$, FFS šiurkščiụ poliụ $R_{n}=1,08$.

Eksperimente naudotos šešios polių išdèstymo schemos (6 pav.). Jomis remiantis galima buvo nagrineti, kaip kinta sąveikos koeficientas keičiantis poliu padèčiai plane. Pirmuoju numeriu pažymèti poliai bandymo metu buvo apkrauti. Likę poliai grupèje sèda tik dèl apkrauto polio itakos. Tarp polių ašių išlaikomas $3 \mathrm{D}$ atstumas. Tarp labiausiai nutolusio neapkrauto ir apkrauto polio ašių yra $12 \mathrm{D}$ atstumas. Taip buvo siekta išsiaiškinti, kokio dydžio yra centriškai apkrauto polio itakos zona. E ir F polių išdèstymo schemos buvo naudotos siekiant išsiaiškinti, ar yra „šešèlio“ ittaka. Tačiau naudojant tokias išdèstymo schemas buvo išbandytos tik dvi lygaus paviršiaus polių grupès tankiame Toyouros smelyje ir nebuvo pastebétas skirtumas tarp bandymu, kai poliai išdéstyti pagal $D$ schemą.

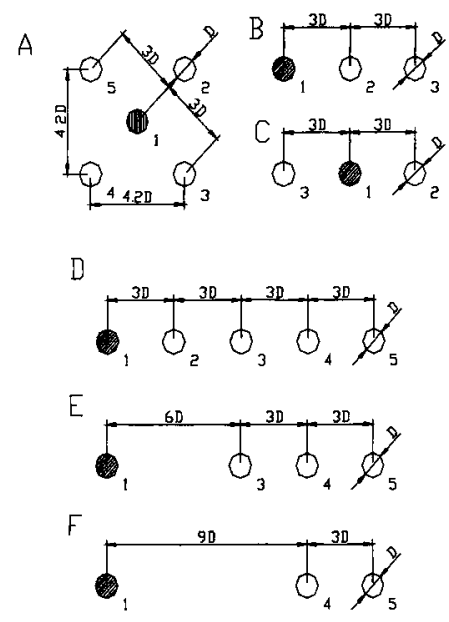

6 pav. Bandytul poliu grupių schemos

Fig 6. The scheme of test pile group

Iš priklausomybių grafiku (7 pav.), nubraižytụ remiantis bandymų rezultatais, galima spręsti, kad nagrinejamas sąveikos koeficientas priklauso ne tik nuo minètụ polio-grunto-polio sistemos parametru, bet ir nuo apkrovos. Didejjant gruntui perduodamai apkrovai, didejja ir sąveikos koeficiento reikšmè. Be to, svarbus ir polio šoninio paviršiaus šiurkštumas: lygiụ polių sq̨veikos koeficientas $\sim 2$ kartus didesnis nei tokioje pat sistemoje esančių šiurkščių polių sąveikos koeficientas. Tai rodo, kad jis priklauso nuo apkrovos perdavimo pagrindui būdo, t. y. nuo to, kokia apkrovos dalis yra perduodama padu bei šoniniu polio paviršiumi.

Taigi eksperimentai patvirtino teigini, kad apkrautas polis, sèsdamas kartu priverčia sèsti ir šalia esanti poli, nors tiesiogiai jis nèra apkrautas jokia papildoma apkrova. Be to, jie parode, kad, kai santykinis atstumas tarp polių $r / D=12 D$, dar jaučiama, nors ir nedidele, apkrauto polio įtaka: šiurkščių polių atveju sąveikos koeficientas $\sim 0,013$, o lygių polių atveju $\sim 0,003$ (kai 
$\left.(Q / Q)_{\max }\right)$. Tačiau, apibendrinus visų bandymų rezultatus ( 8 pav.), buvo pastebeta, kad eksperimentais gauti sąveikos koeficientai yra iki 10 kartų mažesni negu gauti pagal literatūroje rastus ir šiuo metu taikomus sąveikos koeficiento skaičiavimo metodus ( 2 pav.). Be to, tie metodai neivertina sąveikos koeficiento kitimo didèjant apkrovai bei neịvertina atsirandančio skirtumo dèl poliụ paviršiaus šiurkštumo.

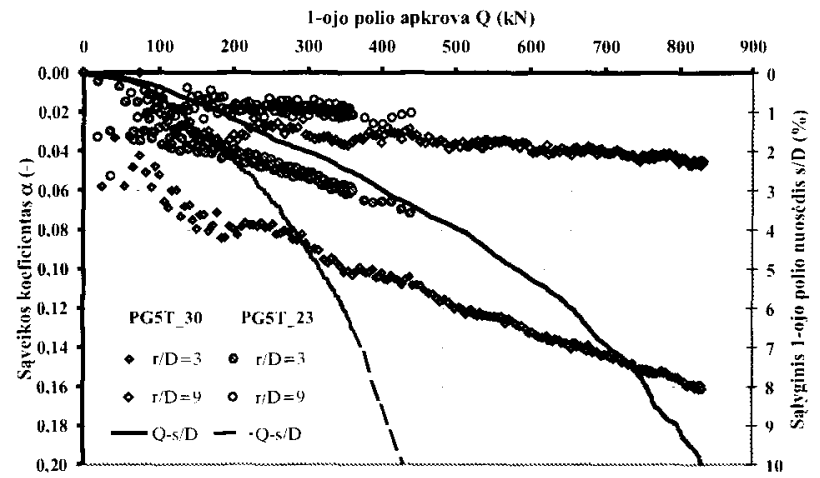

7 pav. Saveikos koeficiento priklausomybè nuo santykinio atstumo $r / D$, polio paviršiaus šiurkštumo bei nagrinejjamu momentu 1-aji poli veikiančios ašinés apkrovos: PG5T_30 - 5 poliu grupe (D schema) irengta tankiame TOS, modeliavimo mastelis $n=30$, polių paviršius šiurkštus; PG5T_23 - 5 polių grupé (D schema) irengta tankiame TOS, modeliavimo mastelis $n=30$, poliu paviršius lygus

Fig 7. The interaction coefficient relationship for normalised distance $r / D$, roughness of pile superficies and axial action of the $1^{\text {st }}$ pile: PG5T_30 - group of five piles (scheme D) installed in dense Toyoura sand, model scale $n=30$, roughness pile superficies; PG5T_23group of five piles (scheme D) installed in dense Toyoura sand, model scale $n=30$, smooth pile superficies

\section{Pagal tamprumo teoriją randamos papildomų nuo- sẻdžių priklausomybès}

1936 m. Mindlinas [11] savo pirmojo uždavinio (9 pav.) sprendinyje pateike ittempimų bei poslinkių priklausomybes bet kuriame tampraus puserdvio taške nuo veikiančios koncentruotos vertikalios jègos.

Supaprastinę polio apkrovos perdavimą pagrindui suskirstysime ji i koncentruotą jègą $Q_{b}$, veikiančią polio pado gylyje ir atitinkančia polio padu perduodamą apkrovos dali, ir polio ašimi veikiančią tolygiai išskirstytą $Q_{s} / L$ apkrovą, atitinkančią polio šoniniu paviršiumi perduodamą apkrovą. Kadangi grunto nuosèdžiai polio pado lygyje yra mažiausi, palyginti su virš šio pavir-

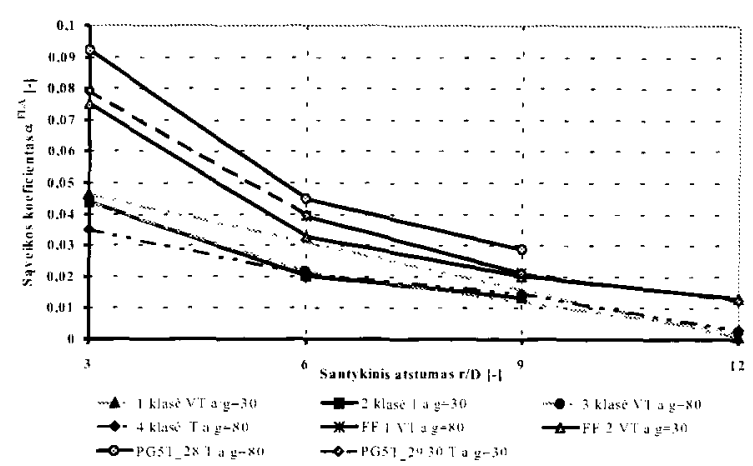

8 pav. Eksperimentinių sąveikos koeficientų priklausomybé nuo santykinio atstumo $r / D$ bei bandytos polis-gruntaspolis sistemos parametru

Fig 8. The experimental interaction coefficient relationship for normalised distance $r / D$ and parameters of tested pile-soil-pile system

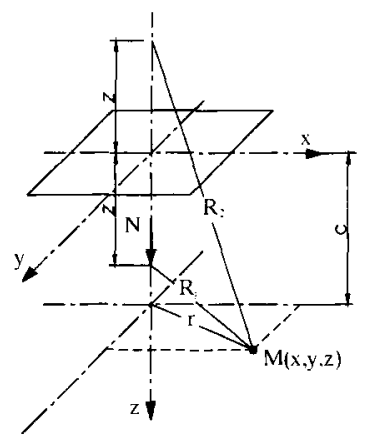

9 pav. Mindlino 1-ojo uždavinio skaičiuojamoji schema

Fig 9. The calculating scheme of the $1^{\text {st }}$ Mindlin problem

šiaus esančio grunto nuosèdžiais, laikausi prielaidos, kad šalia esančių poliụ nuosėdžius riboja polio pado lygyje esančio paviršiaus nuosèdžiai. Todèl, užrašydama apkrauto polio sukeltus greta esančių neapkrautụ poliụ nuosèdžius, atsirandančius nuo polio padu veikiančios $Q_{b}$ jègos, koncentruotai jègai $Q_{b}$ taikau Mindlino pirmojo uždavinio sprendini, ir nuosèdžių grunto polio pado lygyje lygtis:

$$
\begin{gathered}
s_{b}=\frac{Q_{b}}{16 \pi G(1-v)}\left[\frac{3-4 v}{r}+\frac{8(1-v)^{2}-(3-4 v)}{\sqrt{r^{2}+4 L^{2}}}+\right. \\
\left.\frac{4 \cdot L^{2}(3-4 v)-2 \cdot L^{2}}{{\sqrt{r^{2}+4 L^{2}}}^{3}}+\frac{24 \cdot L^{4}}{{\sqrt{r^{2}+4 L^{2}}}^{5}}\right],
\end{gathered}
$$

$G$ - šlyties deformaciju modulis; v - Puasono koeficientas; $L$ - polio ilgis. 


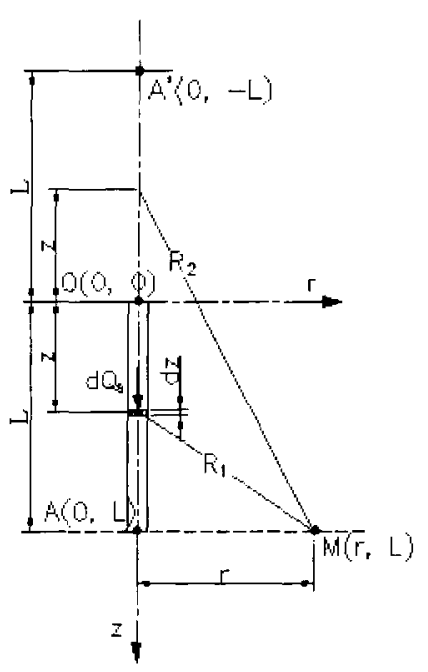

10 pav. Skaičiuojamoji schema polio šoniniu paviršiumi perduodamos apkrovos sukeltiems nuosèdžiams nustatyti

Fig 10. The calculating scheme is designed to find settlement induced by load transmissible by pile superficies

Kai visu polio ilgiu $L$ veikia vertikali vienodai išskirstyta apkrova, tai tam tikrame elementariajame polio elemente $d z$, esančiame tampraus puserdvio $z$ gylyje, veikia koncentruota jèga (10 pav.):

$$
d Q_{s}=\frac{Q_{s}}{L} d z
$$

Sudejję visu polio ilgiu veikiančiu koncentruotụ jègu poveiki gauname nuosėdžiu $s$, atsirandančiu dèl polio šoniniu paviršiumi perduodamos apkrovos, priklausomybę:

$$
\begin{gathered}
s_{s}=\frac{Q_{s}}{4 \pi G L}\left[2 \cdot ( 1 - v ) \cdot \operatorname { l n } \left[\frac{\left.\left|2 L-\sqrt{4 L^{2}+r^{2}}\right|\right]}{\left.L+\sqrt{L^{2}+r^{2}}\right]+}\right.\right. \\
\left.\ln \left[\frac{r}{\sqrt{L^{2}+r^{2}}-L}\right]+\frac{8 L^{3}-2 L r^{2}}{{\sqrt{4 L^{2}+r^{2}}}^{3}}-\frac{5 L \cdot(1-0,8 v)+1}{4(1-v) \sqrt{L^{2}+r^{2}}}\right]+ \\
+C_{1},
\end{gathered}
$$

$C_{1}$ - integravimo konstanta, randama iš kraštinès sąlygos, kad už tam tikro atstumo polio sukelti grunto nuosèdžiai dèl polio šoniniu paviršiumi perduodamos apkrovos lygūs 0 .

Bendri papildomi nuosèdžiai:

$$
s=s_{s}+s_{b} .
$$

Kaip jau buvo mineta 1 skyriuje, itakos koeficiento reikšmei labai svarbus yra pasirinktas šlyties deformaciju modulio kitimo modelis. Be minètụ triju šiuo metu naudojamų šlyties deformacijų modeliu, buvo pasinaudota panašias savybes turinčio Ticino smèlio šlyties deformaciju modulio ties polio-grunto kontaktu priklausomybe nuo apkrauto polio santykinių nuosedžiu bei grunte veikiančių tangentinių ittempimụ priklausomybe nuo apkrovos ir atstumo nuo veikiančio polio.

Iš šių priklausomybių (2), (4) ir (5) gauti papildomi nuosèdžiai, kurie, palyginti su eksperimentiniu būdu gautais neapkrautų polių nuosèdžiais, yra artimi ir priklauso nuo pasirinkto šlyties deformacijų modulio kitimo modelio (11 pav.).

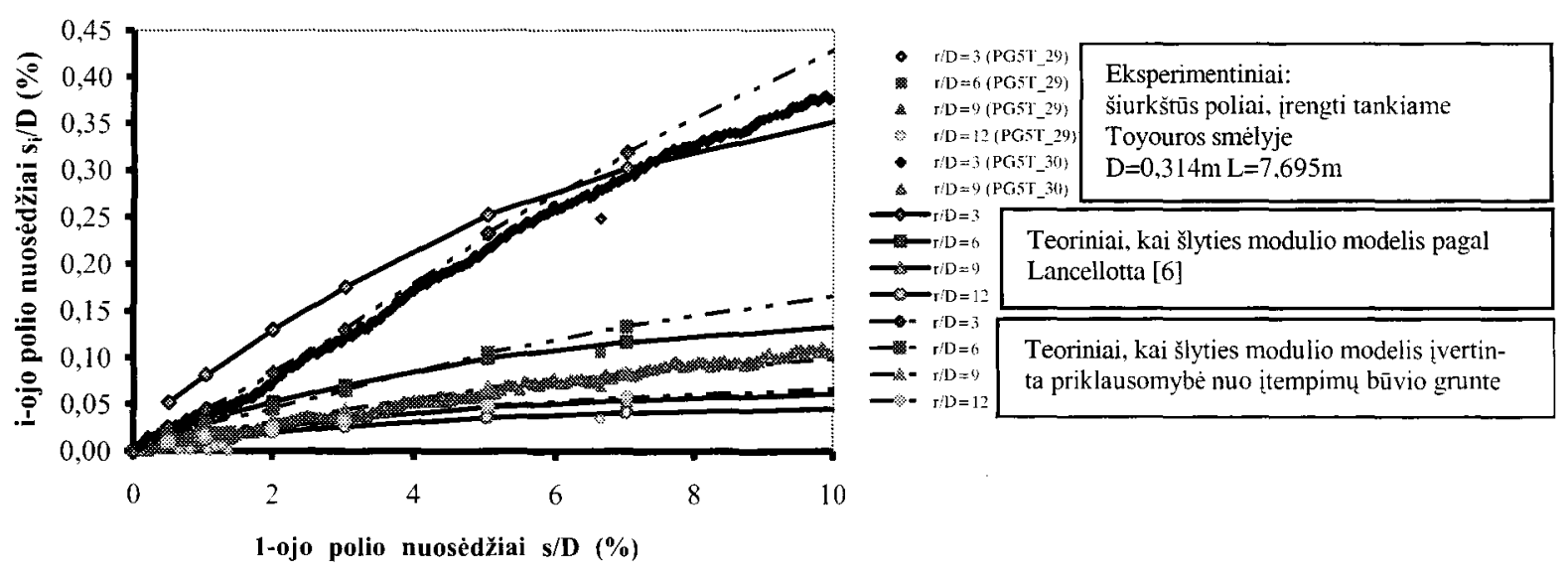

11 pav. Teoriniai bei eksperimentiniai papildomi polių santykiniai nuosédžiai priklausomai nuo apkrauto polio santykinių nuosedžių, santykinio atstumo tarp poliụ $r / D$ bei pasirinkto šlyties modulio kitimo modelio

Fig 11. The theoretical and experimental pile normalised settlements subject to loaded pile normalised settlements, normalised distance between pile $r / D$ and usable variation of shear deformation modules 
Iš 11 paveikslo matyti, kad, remiantis anksčiau užrašytomis priklausomybèmis, papildomų nuosèdžių dydis priklauso nuo pasirinkto šlyties deformacijų modulio $G$ kitimo modelio. Iš gautų rezultatų matyti, kad, kai polio paviršius šiurkštus, tinka šlyties deformacijų modulio kitimo modelis [9], kuriuo remiantis, šalia polio esančio grunto šlyties deformacijų modulis $G$ mažèja didejant apkrauto polio nuosèdžiui.

Kad būtụ išvengta papildomų paklaidų, susijusių su apkrauto polio nuosėdžių tampriosios dalies nustatymu, tampriuosius nuosèdžius galima imti iš eksperimentinių duomenu. Taigi sąveikos koeficientas bus lygus:

$$
\alpha_{E L A}=\frac{s_{i, 1}}{s_{1, E L A}},
$$

$s_{i, 1}-i$-ojo polio papildomi nuosèdžiai, rasti pagal (4); $s_{1, E L A}$ - polio nuosédžio tamprioji dalis, rasta iš eksperimentinių duomenų (12 pav.).

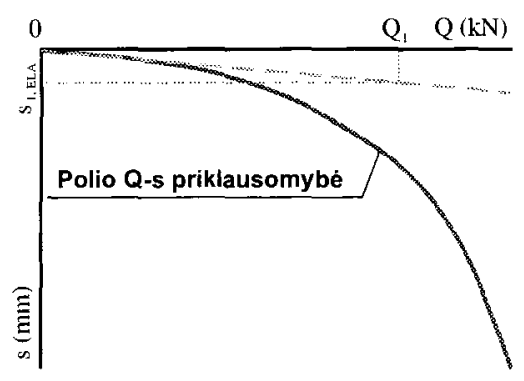

12 pav. Polio nuosèdžio tamprioji dalis pagal eksperimentinę polio $Q-s$ priklausomybę

Fig 12. The elastic part of pile settlement according to experimental $Q-s$ dependence

Pagal (6) lygti bei naudojant eksperimentines priklausomybes $Q-s$ buvo palyginti eksperimentinių įtakos koeficientu priklausomybès nuo santykinio atstumo nuo apkrauto polio ašies su teorinèmis jụ priklausomybèmis. 13 bei 14 paveiksluose pateiktos priklausomybès, gautos poliams su lygiu bei šiurkščiu šoniniu paviršiumi. Remiantis jomis galima teigti, kad priklausomai nuo polių šoninio paviršiaus šiurkštumo tikslinga naudoti skirtingus šlyties deformacijų modulio kitimo modelius.

Kai polio šoninis paviršius lygus $\left(R_{n}<0,10\right)$, jo perduodama apkrova grunto šlyties moduliui už $3 \mathrm{D}$ neturi didelès ịtakos, nes šiuo atveju polio-grunto kontakto vietoje atsiranda kirpimo paviršius, o šlyties deformacijos

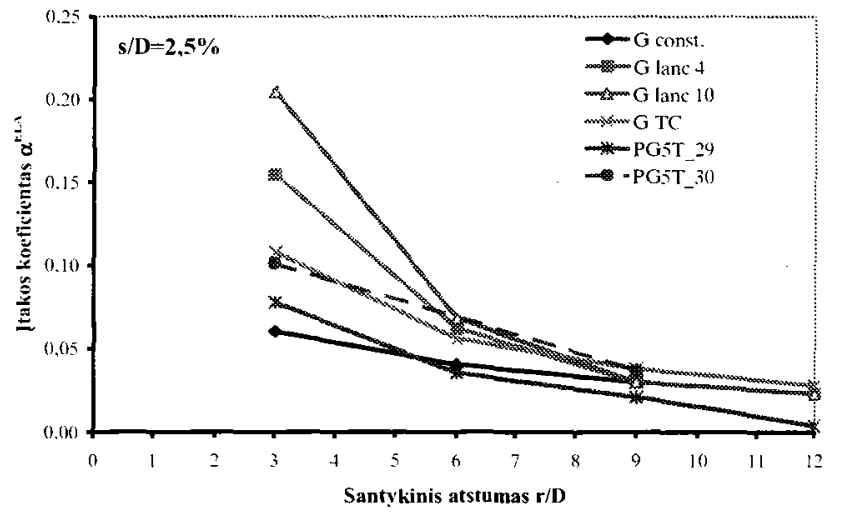

13 pav. Teorinio bei eksperimentinio jtakos koeficiento priklausomybès nuo santykinio atstumo. Teoriniai, kai: $G$ const. - 1-asis $G$ kitimo modelis; $G$ lanc 4 - 2-asis $G$ kitimo modelis; $G$ lanc 10 - 3-asis $G$ kitimo modelis; $G$ TC - 4-asis $G$ kitimo modelis. Eksperimentiniai PG5T_29 ir PG5T_30 - šiurkštiems poliams tankiame Toyouros smèlyje

Fig 13. Theoretical and experimental interaction coefficient dependencies on normalised distance. Theoretical, when: $G$ const. - $1^{\text {st }} G$ variation models, $G$ lanc 4 $2^{\text {nd }} G$ variation models, $G$ lanc $10-3^{\text {rd }} G$ variation models, $G \mathrm{TC}-4^{\text {lh }} G$ variation models; experimental PG5T_29 and PG5T_30 - rough pile installed in dense Toyoura sand

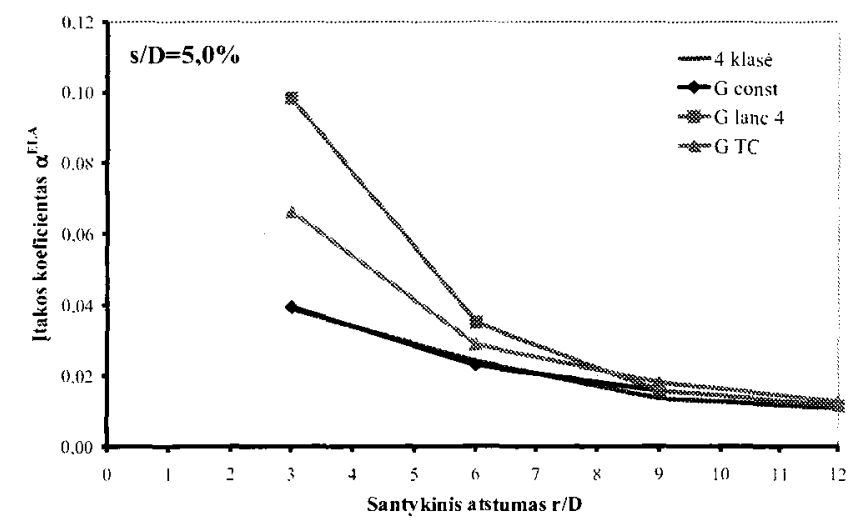

14 pav. Teorinio bei eksperimentinio itakos koeficiento priklausomybès nuo santykinio atstumo. Teoriniai, kai: $G$ const. -- 1-asis $G$ kitimo modelis; $G$ lanc 4 - 2-asis $G$ kitimo modelis; $G$ TC -4 -asis $G$ kitimo modelis. Eksperimentiniai: 4 klasè - poliams lygiu paviršiumi tankiame Toyouros smélyje

Fig 14. Theoretical and experimental interaction coefficient dependencies on normalised distance. Theoretical, when: $G$ const. $-1^{\text {st }} G$ variation models, $G$ lanc 4 $2^{\text {nd }} G$ variation models, $G$ lanc $10-3^{\text {rd }} G$ variation models, $G \mathrm{TC}-4^{\text {th }} G$ variation models; experimental 4 class of test - smooth pile installed in dense Toyoura sand 


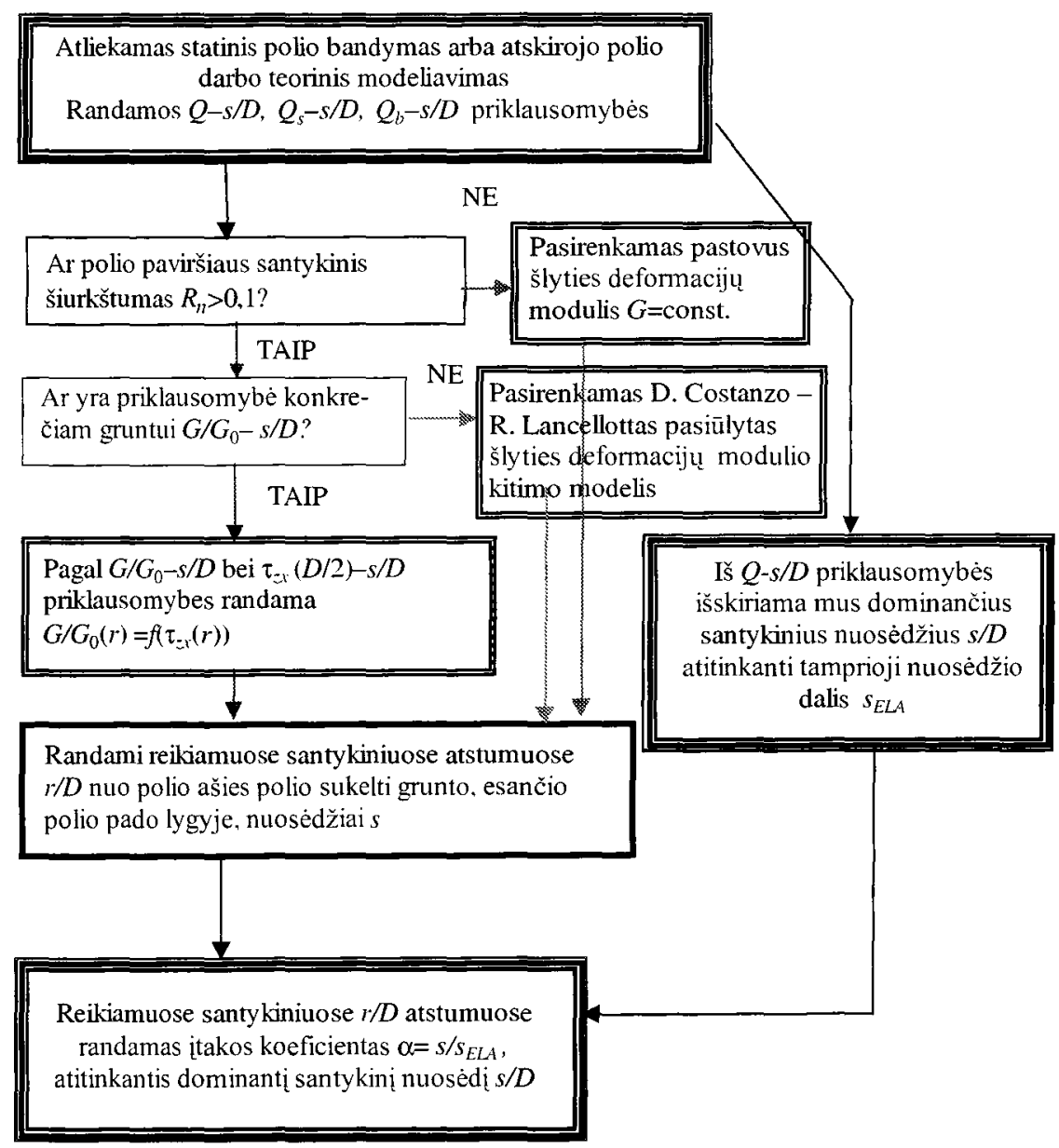

15 pav. Siūlomas itakos koeficiento skaičiavimo algoritmas

Fig 15. Suggested algorithm for calculating the interaction coefficient

nuo polio paviršiaus tolstant nėra tokios didelès, kad jos turètu itakos šlyties deformacijų modulio sumažèjimui. Todèl šiuo atveju tikslinga naudoti pirmaji šlyties deformaciju modulio kitimo modeli, t. y. jis išlieka pastovus ir nepriklauso nuo grunte veikiančių itempimų.

Kai polio šoninis paviršius yra šiurkštus, jei įmanoma, tikslinga itakos koeficiento skaičiavimui naudoti ketvirtaji šlyties deformacijų modulio skaičiavimo modeli, kuriuo juertinama jo priklausomybe nuo grunte esančio ṫtempimo būvio bei apkrauto polio santykinio nuosèdžio. Jei tokios galimybès nèra, galima naudoti D. Costanzo bei R. Lancellotta pasiūlytą šlyties deformaciju moduli, tačiau jis, kol polio santykinis nuosèdis pasiekia $\mathrm{s} / \mathrm{D}=5,0 \%$, duoda didesnes itakos koeficiento reikšmes.

Išnagrinèjus gautus rezultatus buvo sudarytas rekomenduotinas itakos koeficiento skaičiavimo algoritmas (pateiktas 15 pav.).

\section{Išvados}

1. Saqveikos koeficiento reikšmès, apskaičiuotos pagal šiuo metu praktikoje taikomus metodus, yra iki 10 kartų didesnès, negu gautos eksperimentiškai. Eksperimentai patvirtino, kad sąveika tarp poliu, esančiu grupejje, egzistuoja ir jaučiama didesneje nei $12 D$ zonoje.

2. Didelis eksperimentinių ir teorinių itakos koeficientų skirtumas atsiranda dèl to, kad jie neivertina kai kurių svarbių sistemos polis-gruntas-polis parametrų, tokių kaip polio paviršiaus šiurkštumas, šalia esančių polių nuosèdžius ribojančio paviršiaus ties apkrauto polio padu nuosèdžiai; šlyties deformacijų modulio kitimo modeliai neịvertina grunte esančio ittempimų būvio, poli veikiančios apkrovos dydžio.

3. Naudojant Mindlino [11] pirmojo uždavinio sprendinị, galima rasti gręžtinių poliụ, ịrengtụ smèliuose, papildomus nuosèdžius, atsiradusius dèl šalia esančio polio poveikio. 
4. Gautos teorinès reikšmès artimos eksperimentinèms ł̇takos koeficiento reikšmèms. Pasirinktas šlyties deformacijų modulio kitimo modelis turi didelę itaką łtakos koeficiento reikšmèms, todèl svarbu geriau panagrinèti galimus šlyties deformaciju modulio kitimo modelius.

5. Pasiūlytas itakos koeficiento skaičiavimo algoritmas, leidžiantis išnaudoti statybos aikštelèje atliekamus privalomuosius atskiro polio statinius bandymus.

\section{Literatūra}

1. Respublikinès statybos normos ir taisyklès. Gręžininiu pamatu projektavimas ir statyba RSN 91-85. Vilnius, 1986. $55 \mathrm{p}$.

2. Piling Engineering. $2^{\text {nd }}$ edition / Edited by W. G. K. Fleming, A. J. Weltman, M. F. Randolph, W. K. Elson. Blackie Academic \& Professional, Glasgow, 1992. 390 p.

3. H. G. Poulos, E. H. Davis. Pile foundation analysis and design. New York. John Wiley and Sons, 1980. 377 p.

4. D. Sližytė. Centriškai apkrautu gręžtiniu poliu tarpusavio sąveikos ivertinimas projektuojant polinius pamatus // Statyba, VII t., Nr. 3. Vilnius: Technika, 2001, p. 201-206.

5. H. G. Poulos. Analysis of settlement of pile groups // Geotechnique, Vol 18, 1968, p. 449-471.

6. H. Sarri, D. Sližytè. Analysis of interaction coefficients for axially loaded piles // iYGEC 2000. University of Southampton, 2000, p. 153-154.

7. D. Costanzo, R. Lancellotta. A note on pile interaction factors // Soils and Foundations, Vol 38, No 4, 1998, p. $25 \mathrm{I}-253$.

8. V. N. Ghionna, M. Jamiolkowski, R. Lancellotta, S. Pedroni. Base capacity of bored piles in sand from in situ tests // Deep Foundations on Bored and Auger Piles. Van Impe (ed.) Rotterdam: Ballkema, 1993, p. 67-75.

9. R. Lancellotta, J. Calavera. Fondazioni. Milano: McGrawHill Libri Italia SRI, 1999. 612 p.

10. Л. В. Фурмонавичюс. Экспериментальное исследование работы сваи в кусте, заглубленном в моренные грунты // ГЕОТЕХНИКА-III. Материалы третьей меж- республиканской конференции Эстонской, Латвийской и Литовской ССР по инженерной геологии, механике грунтов и фундаментостроению. Рижский политехнический институт, 1975 , с. 72-78.

11. R. D. Mindlin. Force at a point in the interior of a semi - infinite solid // Physics 7, 1936, p. 195-202.

Iteikta 20010702

\section{THE INTERACTION ESTIMATION OF PILES BORED IN SAND}

D. Sližytè

\section{Summary}

Usually a pile foundation consists of a pile group. The difference between the behaviour of a single pile and pile group is described by H. Poulos [5] using the coefficient of interaction, which indicates the pile influence on the increasing neighbouring pile settlement, when neighbouring pile is affected by an axial load.

The pile group physical modelling in centrifuge showed that really a value of the interaction coefficient is smaller than that of estimated by the existing methods.

Furthemore the existing methods do not evaluate a load, roughness of lateral surface of pile and shear modulus variation with pile normalised settlement $s / D$. Also they do not evaluate a pile settlement restriction at a depth $\mathrm{L}$.

Therefore it is very important to find the calculating method for estimating the influence between piles. The article shows how the interaction coefficient can be found using theory of elasticity and experimental data of single pile.

Danutè SLIŽYTÉ. PhD student. Dept of Geotechnical Engineering. Vilnius Gediminas Technical University (VGTU), Saulètekio al. 11, LT-2040 Vilnius, Lithuania.

E-mail: danute@st.vtu.lt

Graduate of Vilnius Technical University (presently VGTU) (1994, civil engineer), MSc (1996, civil engineer). Studied at Technical University of Turin (Italy 1999/2000). Author and co-author of 4 research papers. Research interests: axially loaded pile and pile groups, retaining walls and slopes. 